\title{
Practice-changing publications: Pediatric urology - focus on treatment of spina bifida
}

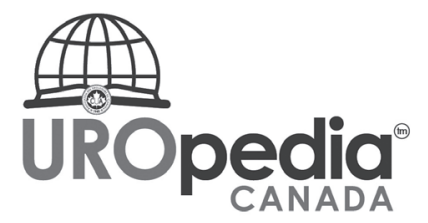

\author{
Peter D. Metcalfe, MD \\ Department of Surgery, Division of Pediatric Surgery, University of Alberta, Stollery Children's Hospital, Edmonton, AB, Canada
}

Cite as: Practice-changing publications: Pediatric urology - focus on treatment of spina bifida. Can Urol Assoc J 2021;15(10):324-5. http://dx.doi.org/10.5489/cuaj.7590

The CUA has introduced a monthly webinar series called Practice-Changing Publications (PCP series), which features Canadian experts discussing recent data that have impacted their field. The CUAJ is proud to present summaries of these talks and the important research discussed in this series.

If you missed any of the webinars, you can access them at https://www.cua.org/UROpedia and earn all-important CPD Section 3 credits!

\section{Introduction}

This article highlights a specific area of pediatric urology - the treatment of spina bifida through a patient's lifetime. Although the fundamental goals of spina bifida treatment have not changed substantially in the past 20 years, the targets of treatment have evolved to span from fetuses to the elderly population.

\section{Fetal surgery}

Fetal surgery has rapidly evolved over the past decade, and several centers have published exciting results in this area. While significant reductions in maternal and fetal mortality and morbidity have been shown in recent years, the procedure is not without significant risk, and requires specialized and dedicated teams. ${ }^{1,2}$ Most studies have demonstrated an improvement in gross motor skills and a decreased need for cerebrospinal fluid (CSF) shunting; however, the data for improved bladder function has been more difficult to interpret. $^{3,4}$ There are several centers that have published good safety and outcome data, ${ }^{2,5}$ but all authors are in agreement that these are extremely complicated undertakings and should only be done in centers of excellence.

Following myelomeningocele closure, many patients are started on clean intermittent catheterization $(\mathrm{CIC})$ regardless of documentation of retention. However, some pro- grams opt for an expectant approach and institute CIC only once indicated. ${ }^{6}$

\section{Multidisciplinary clinic in the neonatal and infant period}

In the neonatal and infant period, the standard of care involves the patient and family participating in a comprehensive, multidisciplinary clinic, which has recently been shown to have long-term benefits for renal health. ${ }^{7}$ From a urological perspective, the primary focus of assessment is the promotion of long-term renal health. Patients are regularly monitored clinically with ultrasound and urodynamics (for urinary tract infections, problems with catheterization, etc.).

\section{Managing continence at school age}

Once patients reach school age, continence becomes a priority. Overall, contemporary data reports a continence rate of approximately $50 \%$, with most responding to $\mathrm{CIC}$ and bladder relaxant medication (anti-muscarinic or beta-agonist). ${ }^{8}$ Patients who fail conservative measures may respond to surgical intervention, although an improvement in quality of life is hard to prove. ${ }^{9}$ Still, long-term associations with continence and quality of life are readily accepted. ${ }^{10}$

\section{Independence and sexual health at adolescence and young adulthood}

With the advent of adolescence, discussions with patients should start to introduce transition to independence and sexual health. Independence is associated with better longterm outcomes. ${ }^{11}$ Discussing sexuality with adolescents is never easy, but it has become very clear that this has been sorely overlooked in the care of spina bifida patients and should be addressed in both male and female patients. ${ }^{2,13}$

The primary goal of the young adult with spina bifida is achieving independence, which likely involves moving out of the family home and entering the workforce. Medical care is often problematic at this stage, and the field of trans- 
lational care has evolved so as to minimize disruption in specialized care and regular medical visits. Guidelines and suggestions for successful transition have been published. ${ }^{14}$ There is such enormous variability with respect to the individual/family needs and availability of local resources that a universal policy is not practical, but the generalities can be used to guide practice.

\section{The aging patient}

Finally, with the success of intensive medical care, the aging spina bifida patient is facing new and more complex medical threats. A recent review by Szymanski (unpublished) of mortality in adults with spina bifida reinforces the complex, mulitifaceted nature of the challenges. Although renal failure is still a common problem in the older population, most spina bifida-related deaths are from infectious and neurological causes.

\section{Conclusions}

Treatment of this complex patient group continues to evolve, with respect to treatment modalities, the age of patients, and achieving an evidence-based approach.

Competing interests: The author reports no competing personal or financial interests related to this work.

\section{References}

1. Adzick NS, Thom EA, Spong CY, et al. A randomized trial of prenatal vs. postnatal repair of myelomeningocele. New Engl J Med 2011;364:993-1004. https://doi.org/10.1056/NEJMoa1014379

2. Moehrlen U, Ochsenbein N, Vonzun L, et al. Fetal surgery for spina bifida in Zurich: Results from 150 cases. Pediatr Surg Int 2021;37:311-6. https://doi.org/10.1007/s00383-020-04824-8

3. Brock JW, Carr MC, Adzick NS, et al. Bladder function after fetal surgery for myelomeningocele. Pediatrics 2015;136:e906-13. https://doi.org/10.1542/peds.2015-2114d

4. Tulipan N, Wellons JC, Thom EA, et al. Prenatal surgery for myelomeningocele and the need for cerebrospinal fluid shunt placement. J Neurosurg Pediatrics 2015;16:613-20. https://doi. org/10.3171/2015.7.PEDS15336

5. Grivell RM, Andersen C, Dodd JM. Prenatal vs. postnatal repair procedures for spina bifida for improving infant and maternal outcomes. Cochrane Database Syst Rev 2014;10:CD008825. https://doi. org/10.1002/14651858.CD008825.pub2

6. Snow-Lisy DC, Yerkes EB, Cheng EY. Update on urological management of spina bifida from prenatal diagnosis to adulthood. J Urol 2015; 194: 288-96. https://doi.org/10.1016/i.juro.2015.03.107

7. Chu DI, Liu T, Patel P, et al. Kidney function surveillance in the National Spina Bifida Patient Registry: A retrospective cohort study. J Urol 2020;204:578-86. https://doi.org/10.1097/JU.0000000000001010

8. Johnston AW, Wiener JS, Purves JT. Pediatric neurogenic bladder and bowel dysfunction: Will my child ever be out of diapers? Eur Urol Focus 2020;6:838-67. https://doi.org/10.1016/i.euf.2020.01.003

9. MacNeily AE, Jafari S, Scott H, et al. Health-related quality of life in patients with spina bifida: A prospective assessment before and after lower urinary tract reconstruction. J Urol 2009;182: 1984-91. https://doi.org/10.1016/i.juro.2009.02.060

10. Liu JS, Dong C, Casey JT, et al. Quality of life related to urinary continence in adult spina bifida patients. Centr Euro J Urol 2015;68:61-7. https://doi.org/10.5173/ceju.2015.01.494

11. Jenkins AM, Burns D, Horick R, et al. Adolescents and young adults with spina bifida transitioning to adulthood: A comprehensive community-based needs assessment. Acad Pediatr 2021;21:858-67. https://doi.org/10.1016/i.acap.2021.02.002

12. Motta GL, Quiróz Y, Llorens $\mathrm{E}$, et al. The impact of neurogenic bladder bowel dysfunction in the sexuality of female spina bifida patients. J Pediatr Urol 2021;17:288.el-6. https://doi.org/10.1016/i. acap.2021.02.002

13. Streur CS, Corona L, Smith JE, et al. Sexual function of men and women with spina bifida: A scoping literature review. Sex Med Rev 2021;9:244-66. https://doi.org/10.1016/i.sxmr.2020.09.001

14. Logan LR, Sawin KJ, Bellin MH, et al. Self-management and independence guidelines for the care of people with spina bifida. J Ped Rehab Med 2020;13:583-600. htrps://doi.org/10.3233/PRM-200734

Correspondence: Dr. Peter D. Metcalfe, Department of Surgery, Division of Pediatric Surgery, University of Alberta, Stollery Children's Hospital, Edmonton, AB, Canada; pmetcalf@ualberta.ca 